\title{
Article \\ Implications of the Symbiotic Nitrogen Fixation in Common Bean under Seasonal Water Stress
}

\author{
Ana P. Rodiño ${ }^{1}$, Manuel Riveiro ${ }^{2}$ and Antonio M. De Ron ${ }^{1, *}$ \\ 1 Biology of Agrosystems, Misión Biológica de Galicia (MBG)-National Spanish Research Council (CSIC), \\ El Palacio-Salcedo, 36143 Pontevedra, Spain; aprodino@mbg.csic.es \\ 2 Experimental Agricultural Station Baixo Miño-INGACAL, 36470 Salceda de Caselas, Spain; \\ manuel.riveiro.leira@xunta.es \\ * Correspondence: amderon@mbg.csic.es; Tel.: +34-986854800
}

Citation: Rodiño, A.P.; Riveiro, M.; De Ron, A.M. Implications of the Symbiotic Nitrogen Fixation in Common Bean under Seasonal Water Stress. Agronomy 2021, 11, 70. https://doi.org/10.3390/ agronomy11010070

Received: 24 November 2020 Accepted: 28 December 2020 Published: 31 December 2020

Publisher's Note: MDPI stays neutral with regard to jurisdictional clai$\mathrm{ms}$ in published maps and institutional affiliations.

Copyright: (C) 2020 by the authors. Licensee MDPI, Basel, Switzerland. This article is an open access article distributed under the terms and conditions of the Creative Commons Attribution (CC BY) license (https:// creativecommons.org/licenses/by/ $4.0 /)$.

\begin{abstract}
The objective of this research was to study the performance of 10 common bean genotypes under water deficit stress and how it affects to their symbiotic relationship with 10 Rhizobium strains in both greenhouse and field conditions. PHA-0471, a small seeded genotype had the best yield under irrigation and under water stress. Other genotypes with tolerance to drought were the largeseeded PHA-0432 and PHA-0683. In the Rhizobium inoculation tests it was observed that the increase of dry nodular weight produced less seed yield in beans. PHA-0683 genotype presented a great uniformity on nodule size and an association with yield when it displays the big nodule phenotype. Further research about this would be interesting because this fact could be due to the existence of a plant blocking mechanism for inefficient strain nodules. The inoculated plants were productive in irrigated fields and in drought ones and their productivity was the same or even better than the $\mathrm{N}$ supplemented plant control. The genotype-strain relationship was very specific and the local strains achieved the greatest productivity with some genotypes in irrigated and drought conditions that make possible their use as inoculating strains, with relevance for the environmental impact of agriculture.
\end{abstract}

Keywords: drought; genetic resources; Phaseolus vulgaris L.; plant breeding; rhizobia; stress

\section{Introduction}

The common bean (Phaseolus vulgaris L.) is produced worldwide as an important protein crop and an alternative to animal protein in the human diet [1]. This crop contains also vital nutrients including vitamins and minerals, and the stems are also used as fodder for livestock, especially in the dry spell following the main cropping season [2].

Drought stress is a major yield-limiting factor in dry bean production worldwide $[3,4]$ especially in marginal, unfavorable environments [5]. Most common bean production in the developing world occurs under conditions where the risk of drought is high [3]. Over $60 \%$ of dry bean production worldwide is subject to water-deficit stress at some stage of growth [6], with yield losses up to $80 \%$ resulting from drought in some regions [7]. Therefore dry bean varieties that retain yield potential under drought stress are a focus of breeding programs [3,8,9]. Drought stress in beans can elicit numerous plant responses including reduced root, shoot, and leaf development, poor nutrient uptake, reduced photosynthesis, stomatal conductance, leaf area, and biomass, inefficient partitioning of carbohydrates, and reduced pod set and seed yield [3,8,10].

Dry bean yield is very sensitive to water deficit stress during the reproductive phase (flowering and pod elongation) [11,12]. Irrigation is often used in dry bean production to reduce drought effects or at least manage it to maximize bean yield or improve water use efficiency when rainfall is limited. The best option for reducing such yield gaps and realizing yield stability under unfavorable environments is the development of droughttolerant genotypes. Drought tolerance, once genetically encoded in the seed of a genotype, 
can be used readily by many farmers for combating drought effects in common bean production [5]. Breeding for drought-tolerant crops is challenging and time-consuming, owing to the need for simultaneously considering multiple abiotic and biotic factors modulating the level of drought-tolerance.

As legumes, common bean plants, also contribute to soil fertility enhancement through symbiotic atmospheric nitrogen fixation [13]. The importance of the Rhizobium-bean symbiosis lies in the ability to transform atmospheric nitrogen into an assimilable one to the plant, through the nodules. Initially, all rhizobia found in beans were assigned to the species R. leguminosarum bv. phaseoli. Currently they are framed in the genus Rhizobium and Sinorhizobium but R. etli predominates in beans. Although, the symbiosis with other species and even other genera was described and it is possible that there exists a great diversity of rhizobium-beans interactions $[14,15]$. Five species have been identified that can nodule with the common bean in the soils of Spain [16]. Effective nodulation by the symbiotic nitrogen-fixing bacterium Rhizobium is difficult to achieve in certain soil types and environmentally stressed conditions [17]. Low humidity, soil salinity and high temperatures in the root zone adversely affect rhizobial survival and infection of bean roots, nodule formation, and development of the enzymatic system that participates in the symbiotic system for N2-fixation [18,19]. The high loss of plant water by evapotranspiration due to high temperatures is also stressful.

Previous efforts have been made to increase the drought tolerance and manage the growth and performance of legumes under conditions of drought stress [20]. These studies documented the important benefits of establishing an efficient Rhizobium-bean symbiosis, but lack the field assessments needed to evaluate, identify and recommend high-performing biofertilizer strains that can be used with confidence to alleviate drought when cultivated in various agroecosystems. Biofertilization of legumes improves soil fertility and decreases groundwater pollution by avoiding the excessive application of chemical fertilizers. Most importantly, description of comprehensive field inoculation experiments is needed to address many issues required to formulate and implement a biofertilization technology based in Rhizobium for field management of the bean crop under these stresses over broad agrosystems.

That lack of a proven rhizobia biofertilizer efficacy based on extensive agronomic field assessments justifies the present study. The general objective of this research was to study the performance of common bean genotypes under water deficit stress and how this stress affects the symbiotic relationship between the bean plants and different Rhizobium strains. For this goal, the experimental tasks were carried out in factorial trials in both controlled conditions in greenhouse and in an open field under water stress and without stress.

\section{Materials and Methods}

Experimental design. Two factorial trials including 10 bean genotypes inoculated with 10 strains of Rhizobium were carried out under conditions of water deficit stress and irrigation in a greenhouse and in an open field (Figure 1). The trials were conducted at the Baixo Miño Agricultural Experimental Station (Salceda de Caselas, Spain, $42^{\circ} 4^{\prime} \mathrm{N}, 8^{\circ} 34^{\prime} \mathrm{W}$, 85 masl). The bean genotypes used belong to the germplasm collection at the MBG-CSIC (Pontevedra, Spain), while the Rhizobium strains were collected in different soils in the region (Galicia, NW of Spain) (Table 1).

The first treatment consisted of water supply both in a greenhouse and in an open field: non-stress (NS), in which the plants were irrigated to maintain between $80-$ and $100 \%$ of field capacity and drought stress (DS), in which it has been tried that the humidity did not fall below $40 \%$ of field capacity.

The second treatment was the inoculation with rhizobia. The Rhizobium strains were seeded in Petri dishes with YMA medium (Yeast Mannitol Agar) and incubated at $25^{\circ} \mathrm{C}$ for three days. The rhizobia colonies were extracted and dissolved in distilled water at a concentration of $10^{8}$ cells $/ \mathrm{mL}$. The concentration was determined by measuring the turbidity with a spectrophotometer (Nanodrop 2000, Thermo Fisher Scientific, Waltham, 
Massachusetts, US). Before inoculation, the seeds were washed in a $10 \%$ bleach solution (5.25\% sodium hypochlorite) to avoid contamination. The seeds, once inoculated, were stored in a polythene bag to retain moisture [21].

(A)

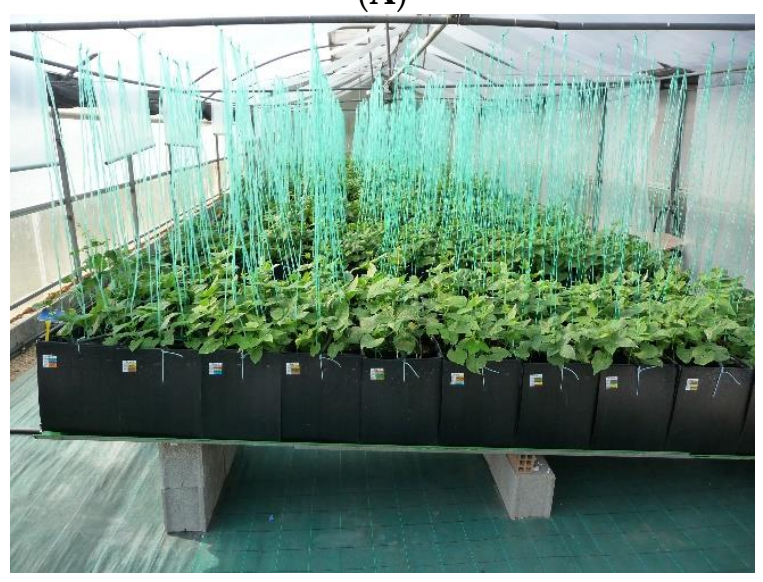

(B)

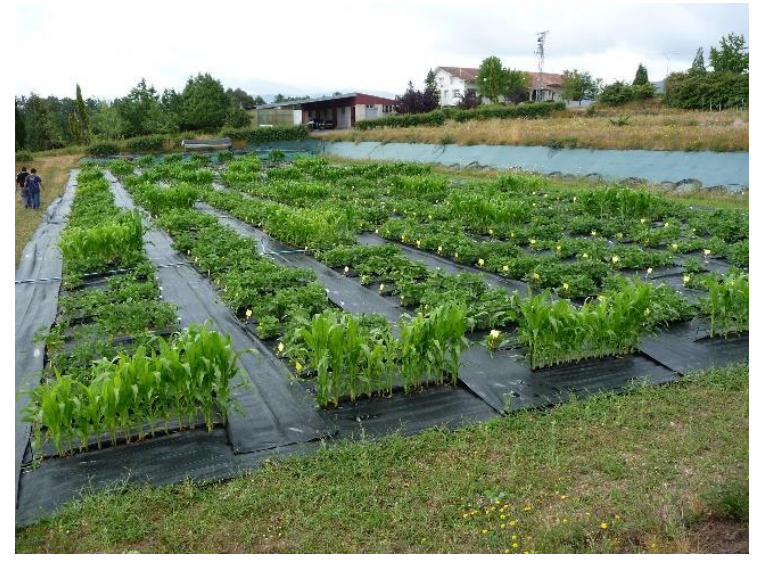

Figure 1. (A) Greenhouse experiment and (B) field experiment.

Table 1. There were three genotypes of beans and two strains of rhizobia of reference (R).

\begin{tabular}{|c|c|c|c|}
\hline \multicolumn{4}{|c|}{ A. Bean genotypes used in this study, name, commercial class and performance under drought. } \\
\hline Bean Genotypes & Name & Commercial Class & Drought Performance \\
\hline PHA-0155 & local variety & White Kidney & unknown \\
\hline PHA-0432 & local variety & Marrow & unknown \\
\hline PHA-0471 & local variety & Navy & unknown \\
\hline PHA-0483 & local variety & Guernikesa & unknown \\
\hline PHA-0683 & local variety & Cranberry & unknown \\
\hline PMB-0220 & Mattherhorn & Great Northern & tolerant \\
\hline PMB-0222 & Almonga & Great Northern & unknown \\
\hline PMB-0244 & Linex $(\mathrm{R})$ & Cannellini & unknown \\
\hline PMB-0285 & L88-18 (R) & Black Turtle & sensitive \\
\hline PMB-0286 & L88-63 (R) & Black Turtle & tolerant \\
\hline \multicolumn{4}{|c|}{ B. Rhizobia strains used. } \\
\hline \multicolumn{2}{|c|}{ Strains of Rhizobia } & \multicolumn{2}{|c|}{ Type } \\
\hline \multicolumn{2}{|c|}{ SLL2 } & \multicolumn{2}{|c|}{ local strain } \\
\hline \multicolumn{2}{|c|}{ EXIC } & \multicolumn{2}{|c|}{ local strain } \\
\hline \multicolumn{2}{|c|}{ EXIB } & \multicolumn{2}{|c|}{ local strain } \\
\hline \multicolumn{2}{|c|}{ EG } & \multicolumn{2}{|c|}{ local strain } \\
\hline \multicolumn{2}{|c|}{$\mathrm{EF}$} & \multicolumn{2}{|c|}{ local strain } \\
\hline \multicolumn{2}{|c|}{ EPOB } & \multicolumn{2}{|c|}{ local strain } \\
\hline \multicolumn{2}{|c|}{ APAFI } & \multicolumn{2}{|c|}{ local strain } \\
\hline \multicolumn{2}{|c|}{ LTMF } & \multicolumn{2}{|c|}{ local strain } \\
\hline \multicolumn{2}{|c|}{ CIAT899 (R) } & \multicolumn{2}{|c|}{ R. tropici } \\
\hline \multicolumn{2}{|c|}{ CFN42 (R) } & \multicolumn{2}{|c|}{ R. etli } \\
\hline
\end{tabular}

According to this, the experiments both in the greenhouse and in the field included 100 combinations: 10 bean genotypes $\times 10$ rhizobia strains each one.

Greenhouse trial. Coconut fiber and vermiculite were used as a substrate in a 2:1 ratio. The bean genotypes were seeded in $35 \times 100 \times 42 \mathrm{~cm}$ double layer polypropylene boxes These boxes had four internal divisions of $200 \mu \mathrm{m}$ polyethylene to isolate the experimental plots. The boxes had a drainage system with 20 holes of $20 \mathrm{~mm}$ in their lower part covered with acrylic textile to avoid the loss of substrate. In each plot of $0.35 \times 0.20 \mathrm{~m}$ eight bean seeds were sown. This experiment included four replications. 
Field trial. The soil texture was sandy loam (62.0\% sand, $26.6 \%$ silt and $11.4 \%$ clay). The experimental plot had $0.75 \mathrm{~m}^{2}$, the distance between rows was $0.50 \mathrm{~m}$ and between bean plants $0.10 \mathrm{~m}, 15$ plants were grown in each plot, with two replications; the two replications that were inoculated with the same strain were sown side by side to avoid mixing of strains. Among the bean plots inoculated with different strains of rhizobia, three rows of maize were planted as a barrier to avoid the mixture of rhizobia strains, since the bacteria are not able to propagate across the maize roots. As controls, the 10 genotypes were grown without fertilization and with nitrogen fertilization $\left(40 \mathrm{~kg} \mathrm{ha}^{-1}\right)$.

The traits measured (Table 2) were: shoot dry weight (SDW); root dry weight (RDW); nodules number (NN); nodule dry weight (NDW); medium nodular dry weight (MNDW), calculated as MNDW = NDW/NN; 100 seed weight (100 SW) adjusted to $12 \%$ moisture content; seed dry matter (SDM); percentage of nitrogen in shoot dry matter (PNSDW), using the Kjeldahl method; quantity of nitrogen in shoot dry matter (NSDW), calculated as $\mathrm{NSDW}=(\mathrm{SDW} \times \mathrm{PNSDW}) / 100$; percentage of nitrogen in seed dry matter $(\mathrm{PNSEDM})$ and nitrogen content in seed dry matter $(\mathrm{NSEDM})$, calculated as NSEDM $=(\mathrm{SDM} \times \mathrm{PNSEDM}) / 100$.

Table 2. Traits measured ( $\mathrm{F}=$ field, $\mathrm{G}=$ greenhouse), acronym and units of measurement.

\begin{tabular}{|c|c|c|}
\hline Traits Measured & Acronym & Units \\
\hline Shoot dry weight, F, G & SDW & grams plant $^{-1}$ \\
\hline Root dry weight, G & RDW & grams plant $^{-1}$ \\
\hline Nodules number, F, G & $\mathrm{NN}$ & number plant ${ }^{-1}$ \\
\hline Nodule dry weight, F, G & NDW & milligrams plant ${ }^{-1}$ \\
\hline Medium nodular dry weight, F, G & MNDW & milligrams \\
\hline 100 seed weight, F & 100SW & grams 100 seeds $^{-1}$ \\
\hline Seed dry matter, $\mathrm{F}$ & SDM & grams plant $^{-1}$ \\
\hline Percentage of nitrogen in shoot dry matter, $\mathrm{F}$ & PNSDW & $\%$ \\
\hline Quantity of nitrogen in shoot dry matter, F & NSDW & grams plant $^{-1}$ \\
\hline Percentage of nitrogen in seed dry matter, $\mathrm{F}$ & PNSEDM & $\%$ \\
\hline Nitrogen content in seed dry matter, F & NSEDM & grams plant $^{-1}$ \\
\hline
\end{tabular}

Data analyses. Analysis of variance was performed for the quantitative characters measured in the trials using the SAS statistical package [22], by the General Linear Model (GLM). The model consists of 10 genotypes (G), two treatments (T) (without and with water deficit stress), 10 strains $(\mathrm{I})$, genotype treatment interaction $(\mathrm{G} \times \mathrm{T})$, genotype strain interaction $(\mathrm{G} \times \mathrm{I})$, treatment strain interaction $(\mathrm{T} \times \mathrm{I})$, genotype treatment strain interaction $(\mathrm{G} \times \mathrm{T} \times \mathrm{I})$, replications $(\mathrm{R})$ and the model error, where $\mathrm{Y}$ is any of the variables studied $Y=(G+T+I+G \times T+G \times I+T \times I+G \times T \times I+R+$ error $)$. The " $F^{\prime \prime}$ test of variance was carried out to show the existence of significant differences between the origins of variations studied [23]. For the comparison of means, the same GLM procedure was used and the least significant difference of Fisher (LSD) was calculated for the variables that displayed significant differences in the analysis of variance.

\section{Results and Discussion}

\subsection{Greenhouse Experiment}

The analysis of variance (ANOVA) included the independent variables, not MNDW since it is an index. Table 3 shows significant differences among all the genotypes for all the variables studied. The treatment $(\mathrm{T})$ is high significant in all the variables except for dry nodular matter (NDW). There are no significant differences between strains in the variables studied. The interaction genotype and treatment $(\mathrm{G} \times \mathrm{T})$ was significant in SDW, RDW and NN. Thus, the treatment influences the variables studied although it does not influence all the variables in the same way. It is remarkable that there is only $\mathrm{G} \times \mathrm{I}$ interaction in RDW. The rest of the interactions were not significant. In previous works [24,25], genotype-strain specificity was demonstrated. There are strains that increase the productivity of certain 
genotypes, and others do not have the same effect [14,24-27]. This does not agree with our results, since the $G^{*} I$ interaction only displayed significant differences for RDW.

Table 3. Analysis of variance in the greenhouse experiment, displaying genotypes $(G)$, strains (I), treatments $(\mathrm{T})$, genotype strain interaction $(\mathrm{G} \times \mathrm{I})$, genotype treatment interaction $(\mathrm{G} \times \mathrm{T})$, treatment strain interaction $(\mathrm{T} \times \mathrm{I})$ and genotype treatment strain interaction $(\mathrm{G} \times \mathrm{T} \times \mathrm{I})$.

\begin{tabular}{ccccc}
\hline Source of Variation & SDW & RDW & NN & NDW \\
\hline G & $* * *$ & $* * *$ & $* *$ & $* *$ \\
$\mathrm{~T}$ & $* * *$ & $* * *$ & $\mathrm{~ns}$ & $\mathrm{~ns}$ \\
$\mathrm{I}$ & $\mathrm{ns}$ & $\mathrm{ns}$ & $\mathrm{ns}$ & $\mathrm{ns}$ \\
$\mathrm{G} \times \mathrm{T}$ & $* * *$ & $* * *$ & $\mathrm{~ns}$ & $\mathrm{~ns}$ \\
$\mathrm{G} \times \mathrm{I}$ & $\mathrm{ns}$ & $*$ & $\mathrm{~ns}$ & $\mathrm{~ns}$ \\
$\mathrm{~T} \times \mathrm{I}$ & $\mathrm{ns}$ & $\mathrm{ns}$ & $\mathrm{ns}$ \\
$\mathrm{G} \times \mathrm{T} \times \mathrm{I}$ & $\mathrm{ns}$ & $\mathrm{ns}$ & & $\mathrm{ns}$ \\
\hline
\end{tabular}

${ }_{* * *} p<0.0001,{ }^{* *} p<0.001,{ }^{*} p<0.01, \mathrm{~ns}=$ not significant.

The genotypes with the highest score for SDW without stress were PHA-0155, PMB-0222 and PHA-0483 (Table S1). Within each genotype the SDW vary significantly between the different strains used, a fact also observed by Rodiño et al. [25], who found large differences in the development of the plant depending on the inoculated rhizobia strain. PHA-0483 and PMB-0285 reach their highest SDW with strain CFN42 and PMB-0220 with strain EXIC. This great specificity in the strain-genotype makes it necessary to optimize the yield of the improved genotype with the specific strain [14,24-27]. The RDW is similar to previous works [25], with a range of $0.26 \mathrm{~g} \mathrm{plant}^{-1}$ to $4.24 \mathrm{~g} \mathrm{plant}^{-1}$ (Table S1). PMB-0285 (1.86 g plant $\left.^{-1}\right)$ and PMB-0286 (1.74 g plant $\left.^{-1}\right)$ have plants with superficial roots and with many adventitious roots being plants with a better efficiency in the adsorption of nutrients such as phosphorus [28].

The number of nodules per plant (NN) (Table S1) has great variability, with LSD (least significant difference) of 133.8 nodules, values similar to other studies [29]. Nodule formation is a plant-controlled process; therefore, the formation of new nodules in the younger roots is inhibited by existing nodules through systemic $\mathrm{N}$ signals $[25,30,31]$. The genotypes with higher nodulation were PMB-0285 and PMB-0286, with 241.6 and 140.0 nodules plant ${ }^{-1}$ respectively. The combination of EXIB-PMB-0285 displayed 1097.8 nodules plant $^{-1}$. This excessive nodulation could be attributed to a specific interaction. PMB-0285 and PMB-0286 were the genotypes with higher nodule dry weight (NDW) (Table S1), with 183.0 and $81.9 \mathrm{mg} \mathrm{plant}^{-1}$, respectively. The EXIB strain has an NDW of $109.5 \mathrm{mg} \mathrm{plant}^{-1}$, mainly due to the disproportionate growth of the PMB-0285 that reaches $937.8 \mathrm{mg} \mathrm{plant}^{-1}$ of NDW. There was a significant relationship $(p<0.0001)$ between RDW and NDW, which accounts for the $85 \%$ of the genotype-strain combinations of the trial. This could be due to the fact that a larger RDW supposes a larger surface that can be infected by rhizobia. In the case of PMB-0285 and PMB-0286, it may be due to an over nodulation. The mean nodular dry matter (MNDW) (Table S1) was between 0.000 and $3.895 \mathrm{mg} \mathrm{nodules}^{-1}$, similar to that observed by Rodiño et al. [25]. Under irrigation, the genotypes with the highest MNDW mean values were PMB-0222 and PMB-0285 with $1.094 \mathrm{mg}$ and $0.837 \mathrm{mg}$ nodule ${ }^{-1}$, and the EPOB and EF strains with $0.796 \mathrm{mg}$ and $0.713 \mathrm{mg}$ nodule $^{-1}$, respectively. In general, the plants showed very small nodules, with values $<1 \mathrm{mg}$ nodule ${ }^{-1}$ in $90 \%$ of the plants.

The water stress in this experiment represented an average reduction of $32.6 \%$ in SDW. The genotype PHA-0155 had the highest SDW (Table S2) in conditions of water stress, but it does not indicate a tolerance to this stress, since it suffers a reduction of $48.3 \%$, compared to the absence of stress. The genotypes that can be considered drought tolerant are PHA-0471 and PMB-0220 since they displayed around 15\% more SDW in an environment with water stress than without stress. Possibly this increase is due to an adaptation to the drought of the $R$. tropici CIAT899 strain, which induced in these genotypes a considerable increase in SDW. The LTMF, EXIC and SLL2 strains can be defined as sensitive strains since the 
plants inoculated with these strains present a much lower SDW than the rest. In general terms, there was a significant 33\% RDW reduction (Table S2) in plants subjected to water stress. This reduction occurs because the roots are an important carbon sink for the plant and if this is altered the RDW can decrease [32]. The strain-genotype combinations with the highest RDW were LTMF-PMB-0244 and CIAT899-PHA-0683, with values greater than $1.20 \mathrm{~g} \mathrm{plant}^{-1}$.

Water stress shows an average reduction of $57.2 \%$ in NN. The genotypes with the highest NN were PHA-0471 and PHA-0683, with 47.5 and 43.6 nodule plant ${ }^{-1}$, respectively (Table S2). The genotype PHA-0471 nodules well in irrigation, and under water stress conditions it does not suffer a significant reduction. This stability in NN also occurs in some soybean genotypes, and it is a competitive advantage, since if the stress subsides, the plant can quickly regain nitrogen-fixing capacity [33]. The EPOB strain with PHA-0471 reaches maximum nodulation with 84.3 nodules plant ${ }^{-1}$. The genotype with the highest NDW is PHA-0683 with $124.4 \mathrm{mg} \mathrm{plant}^{-1}$ (Table S2), due to the exceptional values of 428.0 and $327.6 \mathrm{mg}$ plant $^{-1}$ obtained with EG and EPOB strains, respectively. The plants inoculated with these strains have the highest NDW with 107.0 and $80.5 \mathrm{mg} \mathrm{plant}^{-1}$ respectively. This response of the bean to the water stress conditions, contrasts with that observed in other legumes such as pea, where the plants reduced their NDW by $62 \%$ under water stress $[34,35]$. This may be due to a worse adaptation of the strains, which would imply lower levels of infection or an early senescence of the nodules due to stress [36-39]. The Table S2 shows that the MNDW values under water stress conditions increase compared to the irrigated experiment. There were genotypes such as PHA-0483 that had a value five times higher for MNDW. The genotypes with the highest MNDW are PHA-0683 and PHA-0483, with $2.307 \mathrm{mg}$ and $2.077 \mathrm{mg}$ respectively. The strains that induce the highest MNDW are EF and EPOB, with $2.410 \mathrm{mg}$ and $2.374 \mathrm{mg}$ on average.

Voisin et al. [35] in their study of nodular self-regulation processes found that the NDW had a direct relationship with the SDW, independently of the number of nodules. Thus, it is logical to assume that if the number of nodules is less, they tend to be larger. PHA-0683 shows great size uniformity in its nodules (Figure 2). When it presents big nodules (BNO) (A), it maintains this size regardless of the $\mathrm{NN}$, and the same happens when they have small nodules (SNO) (B). According to Mergaert et al. [40], BNO-inducing strains appear capable of overcoming plant defense mechanisms. The combination PMB-0222-EPOB presented BNO under irrigation and $\mathrm{SNO}$ in drought conditions. Instead, the combination PHA-0683-EG presented the opposite. Thus, it is shown that the infection mechanisms of the strain and the morphology of the root cells are affected by water stress. The greenhouse experiment was a preliminary study that showed the main trends in the performance of the symbiotic system that was studied in more detail in the field experiment.

\subsection{Field Experiment}

There are significant differences in all the variables studied between the bean genotypes and the treatments(Table 4). Between strains the difference was not significant in some variables related to nodulation (NN, NDW). It is surprising that the strains do not influence nodulation but influence nitrogen fixation, which may suppose that these characters are determined by the genetics of the plant. The interaction $\mathrm{G} \times \mathrm{T}$ was significant for all variables, except NDW, which showed that the genotypes had a differentiated response to water stress, both in dry matter and in the partition of $\mathrm{N}$ in the plant. The $\mathrm{G} \times \mathrm{I}$ and $\mathrm{G} \times \mathrm{T} \times \mathrm{I}$ interactions were only significant for SDW, NSDW, and 100SW. The interaction T $\times$ I was significant for all variables except for those related to nodulation.

Table S3 shows the average production of SDW that in irrigation was $34.2 \mathrm{~g} \mathrm{plant}^{-1}$. In the plants inoculated with the LTMF strain, SDW was significantly higher with $46.7 \mathrm{~g} \mathrm{plant}^{-1}$. The combinations LTMF-PHA-0471 and LTMF-PMB-0285 doubled the SDW, exceeding $70 \mathrm{~g} \mathrm{plant}^{-1}$. The mean value of $100 \mathrm{SW}$ under irrigation was $31.6 \mathrm{~g}$ (Table S3), but there are large differences among genotypes. Despite the fact that the size of the seed is genetically regulated [41,42], there is a certain range of variation within each genotype, since PHA-0155 
had a coefficient of variation of $24 \%$, PMB- $022438 \%$ and PHA- $048340 \%$. The control plants cultivated with $\mathrm{N}$ supply had larger seeds than the rest, $47.2 \mathrm{~g} 100$ seeds $^{-1}$ highlighting PMB-0222, PMB-0285, PHA-0483 and PMB-0244, with increases of $65 \%$ with respect to the mean of the inoculated plants. However, the SDM performance was higher in the inoculated genotypes, except PMB-0244, which shows the efficacy of the symbiotic association.

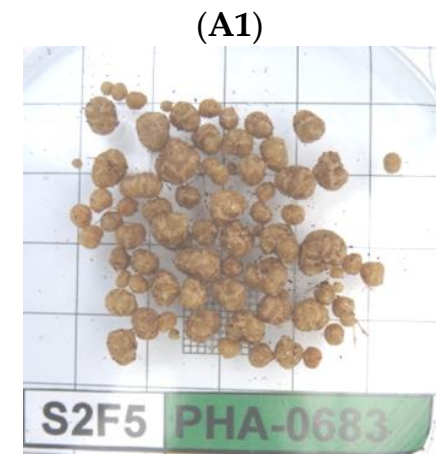

(B1)

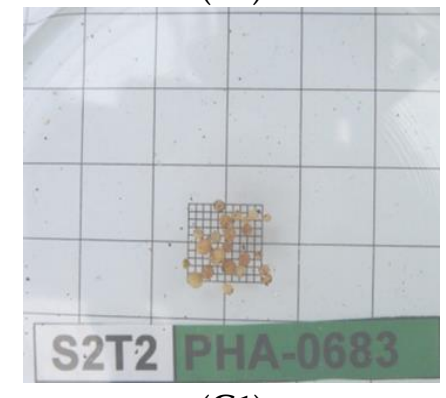

(C1)

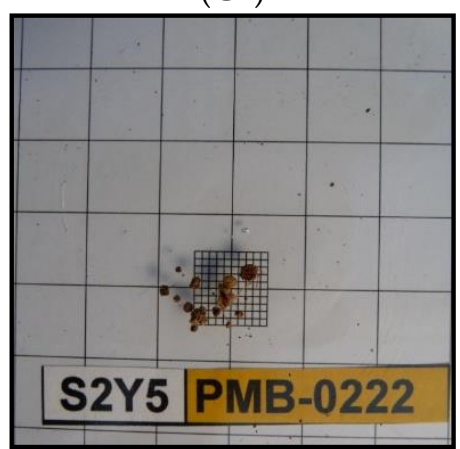

(A2)

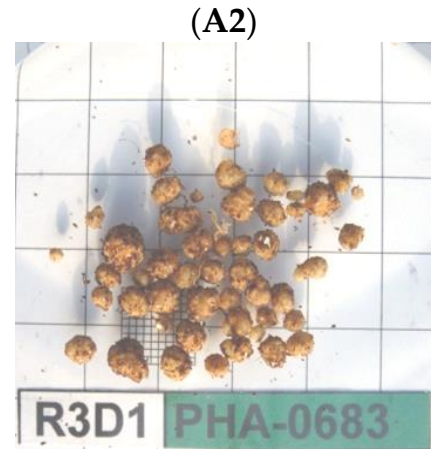

(B2)

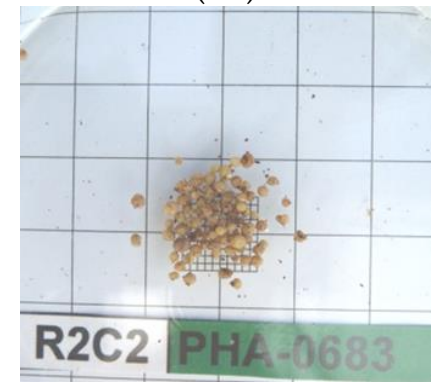

(C2)

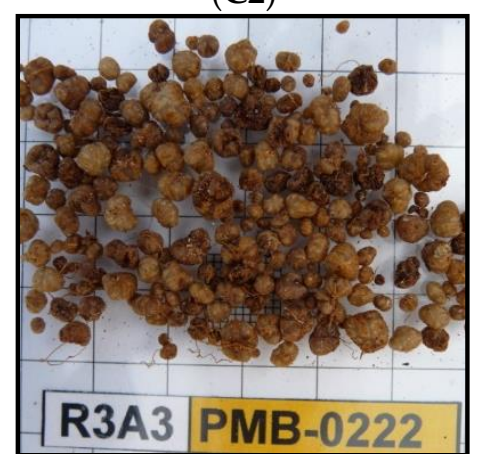

Figure 2. Variation in the size of nodules depending on the bean genotype and the strain. (A1,A2). BNO nodules in PHA-0683. (B1,B2). SNO nodules in PHA-0683. (C1,C2). PMB-0222EPOB combination showing the difference in size in irrigation and drought.

The mean NN was 29.1 nodules per plant. PMB-0286 presents the highest nodulation, with 56.9 nodules plant $^{-1}$. The combination with the highest nodulation was PMB-0286LTMF, with 122.7 nodules plant ${ }^{-1}$. Given the low nodular specificity of the common bean [43], the zero control allows evaluating native populations of the rhizosphere with the capacity to generate nodules. The growth of the native populations of rhizobia is significant when the inoculated populations show a very low nodulation, and instead they can hardly be detected when they present high nodulation. Just as there are inoculated strains that compete well with native populations [44,45], there are also inoculated strains that do not adapt to the environment or do not compete with native ones. The number of nodules is determined by the rate of $\mathrm{N}$ supplied and $\mathrm{N}$ demanded [35]. The control plants with $\mathrm{N}$ presented nodulation, despite those at doses higher than $30 \mathrm{~kg} \mathrm{~N} \mathrm{ha}^{-1}$, early nodulation is reduced [46]. This shows that the degree of $\mathrm{N}$ tolerance is a variable factor linked to the genotype. Rennie and Kemp [47] applied a dose of $40 \mathrm{~kg} \mathrm{~N} \mathrm{ha}^{-1}$ and 
detected genotypes that suffered only a $10 \%$ reduction in $\mathrm{N}$ fixation, while in others the difference was 60\%. In the case of PMB-0286 and PMB-0244, this dose of $\mathrm{N}$ in the initial vegetative phase could have a "starter" effect, which allowed the development of the plant that favored better nodular growth [48]. The average NDW was $29.1 \mathrm{mg} \mathrm{plant}^{-1}$. The genotypes with the highest NDW (Table S3), above $30 \mathrm{mg}^{\text {plant }}{ }^{-1}$ were PMB-0286 and PMB-0285. According to Vessey [48], a higher value would be expected, since bean genotypes with indeterminate growth habit continue to accumulate NDW during the podfilling phase. This low value could be because the plants were collected in the flowering stage and they did not reach their maximum potential. The LTMF-PMB-0286 combination showed a value of $94.1 \mathrm{mg}$ plant $^{-1}$. There is a direct relationship between NDW and SDM, but the relationship varies based on SDM/NDW performance [49]. As NDW increases, SDM per mg of NDW decreases. Genotype-strain combinations with SDM/NDW between 2 and $7 \mathrm{~g}$ show a significant relationship $(p<0.0001)$. Some variation that appears in the nodulation could be due to the incomplete collection of the root system when extracting from the soil [46].

Table 4. Analysis of variance in the field experiment, with genotypes $(\mathrm{G})$, treatments $(\mathrm{T})$, strains $(\mathrm{I})$, genotype treatment interaction $(\mathrm{G} \times \mathrm{T})$, genotype strain interaction $(\mathrm{G} \times \mathrm{I})$, treatment strain interaction $(\mathrm{T} \times \mathrm{I})$, and genotype treatment strain interaction $(\mathrm{G} \times \mathrm{T} \times \mathrm{I})$.

\begin{tabular}{cccccccccc}
\hline & SDW & NSDW & PNSDW & SDM & NSEDM & PNSEDM & NN & NDW & 100SW \\
\hline $\mathrm{G}$ & $* * *$ & $* * *$ & $* * *$ & $* * *$ & $* * *$ & $* * *$ & $* * *$ & $* * *$ & $* * *$ \\
$\mathrm{~T}$ & $* * *$ & $* * *$ & $* * *$ & $* * *$ & $* * *$ & $* * *$ & $* * *$ & $* * *$ & $* * *$ \\
$\mathrm{I}$ & $* * *$ & $* * *$ & $* * *$ & $* * *$ & $* * *$ & $*$ & $\mathrm{~ns}$ & $\mathrm{~ns}$ & $* * *$ \\
$\mathrm{G} \times \mathrm{T}$ & $* * *$ & $* * *$ & $* * *$ & $* *$ & $* *$ & $* * *$ & $* *$ & $\mathrm{~ns}$ & $*$ \\
$\mathrm{G} \times \mathrm{I}$ & $* * *$ & $* * *$ & $\mathrm{~ns}$ & $\mathrm{~ns}$ & $\mathrm{~ns}$ & $\mathrm{~ns}$ & $\mathrm{~ns}$ & $\mathrm{~ns}$ & $*$ \\
$\mathrm{~T} \times \mathrm{I}$ & $* * *$ & $* *$ & $* * *$ & $* * *$ & $* * *$ & $*$ & $\mathrm{~ns}$ & $\mathrm{~ns}$ & $* * *$ \\
$\mathrm{G} \times \mathrm{T} \times \mathrm{I}$ & $* * *$ & $* * *$ & $\mathrm{~ns}$ & $\mathrm{~ns}$ & $\mathrm{~ns}$ & $\mathrm{~ns}$ & $\mathrm{~ns}$ & $\mathrm{~ns}$ & $* * *$ \\
${ }^{* * *} p<0.0001,{ }^{* *} p<0.001,{ }^{*} p<0.01, \mathrm{~ns}=$ not significant. & & & & &
\end{tabular}

The first variable to be analyzed related to the partition of $\mathrm{N}$ in the plant is the percentage of $\mathrm{N}$ in the aerial dry matter (PNSDW), whose mean value in irrigation was $3.15 \%$ (Table S3). PHA-0483, PHA-0683 and PHA-0432 with 3.40\%, were the genotypes with the highest PNSDW while PHA-0155 obtained the lowest percentage with $2.53 \%$. Control plants with N and those inoculated with CIAT899 and CFN42 were significantly higher with $3.36 \%$, while those inoculated with SLL2 and LTMF, with $2.90 \%$ had the lowest. PNSDW can be very stable with respect to SDW as it occurs in PMB-0222 or it can decrease with increasing SDW as observed in PHA-0683 and PMB-0220 (Figure 3). Thus, the stability of PNSDW is a function of how limiting $\mathrm{N}$ may be for each genotype. The mean NSDW in irrigation was $1.06 \mathrm{~g} \mathrm{plant}^{-1}$. PHA-0471 and PMB-0285 (Table S3) displayed values significantly higher, with 1.57 and $1.49 \mathrm{~g} \mathrm{plant}^{-1}$ respectively. The plants inoculated with the LTMF strain obtained the highest NMSA (1.22 g plant $\left.{ }^{-1}\right)$, while the zero and $\mathrm{N}$ control had a significantly lower value than the inoculated plants. PHA-0471 with LTMF was the combination with the highest accumulation of $\mathrm{N}\left(2.25 \mathrm{~g} \mathrm{plant}^{-1}\right)$. N fixation can account for 35 to $70 \%$ of plant N [50].

PNSEDW is determined by genotype and agronomic conditions [51]. In irrigation it was $3.75 \%$ (Table S3). PHA-0471 and PMB-0285, were around $4 \%$ of PNSEDW, and were superior to the rest of the genotypes. The combination PHA-0471-EXIC, reached $4.28 \%$, which was higher than the values by Escribano et al. [52]. The NSEDM ranges from 0.12 to $3.83 \mathrm{~g} \mathrm{plant}^{-1}$ (Table S3), with an average value of $1.53 \mathrm{~g} \mathrm{plant}^{-1}$. PHA-0471 and PMB-0286 had means of 2.22 and $1.96 \mathrm{~g} \mathrm{plant}^{-1}$, respectively. The plants inoculated with CIAT899, EXIC, EPOB and $\mathrm{N}$ control had averages greater than $1.70 \mathrm{~g} \mathrm{plant}^{-1}$. The maximum value was $3.83 \mathrm{~g} \mathrm{plant}^{-1}$ in the combination PHA-0471-CIAT899. N mobility is genetically regulated [53], but the greater or lesser mobilization of $\mathrm{N}$ is not correlated with seed production [54]. The maximum symbiotic nitrogen fixation (SNF) rate occurs before flowering, and it was in flowering when NSDW was determined, observing that the higher 
the NDW, the lower the NSDW. Logic would suggest that NDW would act as a sink for N and only when the filling phase begins, therefore $\mathrm{N}$ would be mobilized towards the seeds.

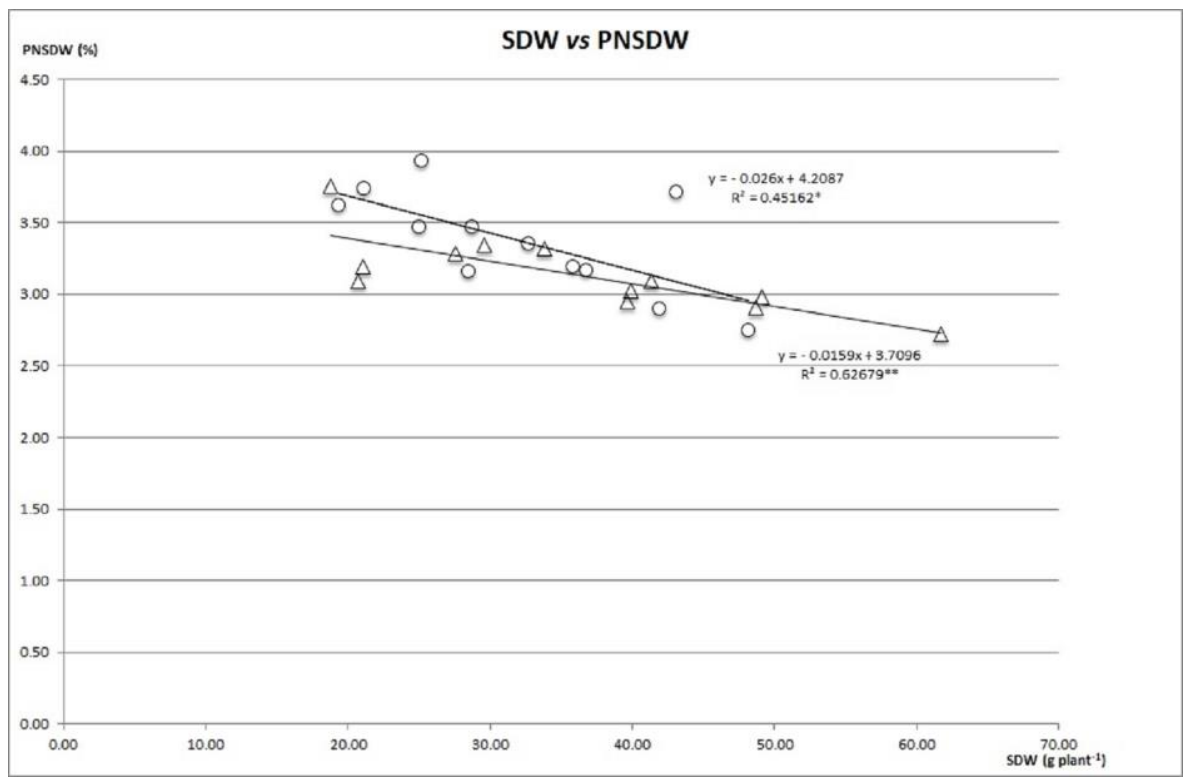

Figure 3. SDW vs. PNMSA ratio of genotypes PHA-0683 and PMB-0220 under irrigation in field. ** $p<001$ and $* p<0.01$.

Under water stress, the plant tends to close its stomata to reduce transpiration, which limits gas exchange, and therefore carbohydrate production decreases. This reduction of carbohydrate production directly affects the total biomass, and limits nitrogen fixation indirectly $[10,33,55]$. This would imply a reduction of $\mathrm{N}$ in the leaves, causing senescence [49] and a reduction in the SDW. Water stress represents a 46\% decrease in SDW, with an average of $18.7 \mathrm{~g} \mathrm{plant}^{-1}$ (Table S4). PHA-0471, despite suffering a reduction of $22.5 \mathrm{~g} \mathrm{plant}^{-1}$, remained, along with the genotype being PMB-0285, PHA-0155 and PMB-0286 the genotypes with the highest production of SDW. The plants inoculated with LTMF and APAFI presented the highest SDW ( $\left.25 \mathrm{~g} \mathrm{plant}^{-1}\right)$. Under water stress conditions, the $100 S W$ values showed a 17\% reduction (Table S4), although this was not uniform for all genotypes. PHA-0471, PHA-0683, PMB-0222 and PMB-0285, had a sTable 100SW under water stress. Singh [56] interprets that it is because water stress produces a partial abortion of the seeds, which generates a greater distribution of photosynthesis in the few seeds that remain. Sadras [57] observed that the small variability in the size of the seeds is associated with some plasticity in the number of seeds per pod. The 100SW stability is not tied to seed size. The plants inoculated with LTMF, SLL2, EPOB, APAFI and EF obtained the highest

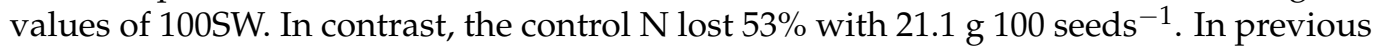
works, N-fertilized plants subjected to water stress also suffered similar reductions that were attributed to a change in direction in the balance of plant-soil $\mathrm{N}$ [58]. Plants under water stress conditions had a drought intensity index (DII) of 0.51 , or what is the same, a reduction of SDM of 51\% (Table S4). The genotype with the highest SDM was PHA0471 with $27.4 \mathrm{~g} \mathrm{plant}^{-1}$. PHA-0432 was the most tolerant to water stress with only a $33 \%$ reduction, but despite this it had the lowest SDM value $\left(13.0 \mathrm{~g} \mathrm{plant}^{-1}\right)$ along with PMB-0244. PMB-0286 (24.7 g plant $^{-1}$ ) was the most sensitive genotype to water stress. The LTMF-PMB-0220 combination obtained the maximum SDM value with $52.9 \mathrm{~g} \mathrm{plant}^{-1}$.

Water stress causes a reduction in the number of absorbent hairs in the plant roots; therefore, by reducing the place where the primary infection occurs, a decrease in $\mathrm{NN}$ is logical $[59,60]$. This stress affects all states of symbiosis, in addition to limiting growth and soil survival of Rhizobium [61-63]. In this trial, nodulation was not affected by water stress, since it did not occur until 35 days after planting (DAS). The nodules of the primary 
nodulation can already be counted in 14 DAS [64]. Once the nodules are formed, water stress does not affect either NN or NDW, although there is a decrease in the SNF rate [65]. This is a competitive advantage, since after stress the plant can regain its N-binding activity [66]. The water stress supposes for all the bean genotypes an increase in the number of nodules per plant, although this increase can only be considered significant in three genotypes: PHA-0432, PHA-0683 and PMB-0285 (Table S4). The variability of the data for each strain was so great that, despite having a range between 45.7 and 69.8 plant $^{-1}$ nodules, there are no significant differences among the inoculated and not inoculated control plants. The maximum value under water stress conditions was 243.0 nodules plant ${ }^{-1}$, which was reached by the combination PHA-0683 with the EXIB strain. The water stress conditions also suppose an increase in NDW of 87\%, although the increase in PHA-0683 can only be considered significant (Table S4). The genotypes with the highest NDW were PMB0286 and PMB-0285, with values higher than $45 \mathrm{mg} \mathrm{plant}^{-1}$. In the control N, PMB-0286 and PMB-0285 registered the highest values, 76.6 and $71.7 \mathrm{mg} \mathrm{plant}^{-1}$, respectively. This indicated that instead of inhibiting the growth of nodules, it acted as a "starter". The combination EXIB-PHA-0683 with $161.1 \mathrm{mg} \mathrm{plant}^{-1}$ reached the highest NDW value. Water stress produces a drastic reduction in the production of SDM/NDW $\left(\mathrm{g} \mathrm{mg}^{-1}\right)$ of $64 \%$. Even so, the same trend was maintained as in irrigation, the higher the NDW, the lower the yield in the production of SDM.

Between 55 and 75 DAP, $88 \%$ of the $\mathrm{N}$ demands of the pods come from the biological fixation of $\mathrm{N}$ [67]. According to some authors [34,68], the plants that have undergone water stress in this interval of the plant cycle also experience a decrease in the dry matter of the plant, and in NSEDM due to the decrease in nitrogenase activity. The mean PNSDW in drought was $2.65 \%$ (Table S4), which represents a reduction of $16 \%$ compared to the irrigated experiment. PMB-0286, PHA-0471 and PMB-0220 were the bean genotypes that experienced the least reduction and those that had the highest PNSDW value under water stress conditions. There are no significant differences between the inoculated plants and the not inoculated controls. LTMF-PMB-0286 was the combination with the highest PNSDW (3.38\%). The PNSDW of PMB-0222, PMB-0244, PMB-0285 and PMB-0286, were independent of SDW in the two treatments, so that $\mathrm{N}$ in these genotypes was a limiting factor. Water stress shows a reduction of more than $50 \%$ of the NSDW and affects almost all genotypes equally, due to the strong $\mathrm{C} / \mathrm{N}$ interaction. The plant subject to water stress limits the flow of $C$ towards the nodules, which causes a decline in N fixation [69]. Despite being PHA-0471 and PHA-0285, the genotypes with the highest drought losses still maintain the highest NSDW. LTMF-PMB-0285 was the combination with the highest NSDW (1.17 g plant $\left.{ }^{-1}\right)$.

The PNSEDW was quite stable under water stress [70], and only presented a decrease of 4\% (Table S4). PHA-0220, PHA-0432 and PHA-0471 were genotypes with PNSEDW greater than $3.75 \%$ while the combinations with the highest PNSEDW were SLL2-PMB0220 and $\mathrm{N}$ control-PHA-0432, with values greater than $4.40 \%$. Water stress implied a $53 \%$ reduction in NSEDM, mainly due to a 51\% reduction in SDM, since the percentage of $\mathrm{N}$ in seed (PNSEDW) is hardly affected by water stress. PMB-0220- LTMF achieves the maximum value with $1.97 \mathrm{~g} \mathrm{~N}$ plant $^{-1}$. Under water stress conditions, there is less dispersion of the NSDW and NSEDM data, which indicated the linear correlation between the two variables (Figure 4). This may be because the shortage of N produced by water stress forces the plant to use $\mathrm{N}$ more efficiently. There is a significant relationship between SDM and NSEDM; Araujo and Grandi-Teixeira [71] demonstrated this relationship and that it also occurs with total P and SDM, so it can be said that great or less SNF will determine a greater or lesser production of SDM. The results from the field experiment consolidate the preliminary greenhouse data on symbiotic efficiency. 


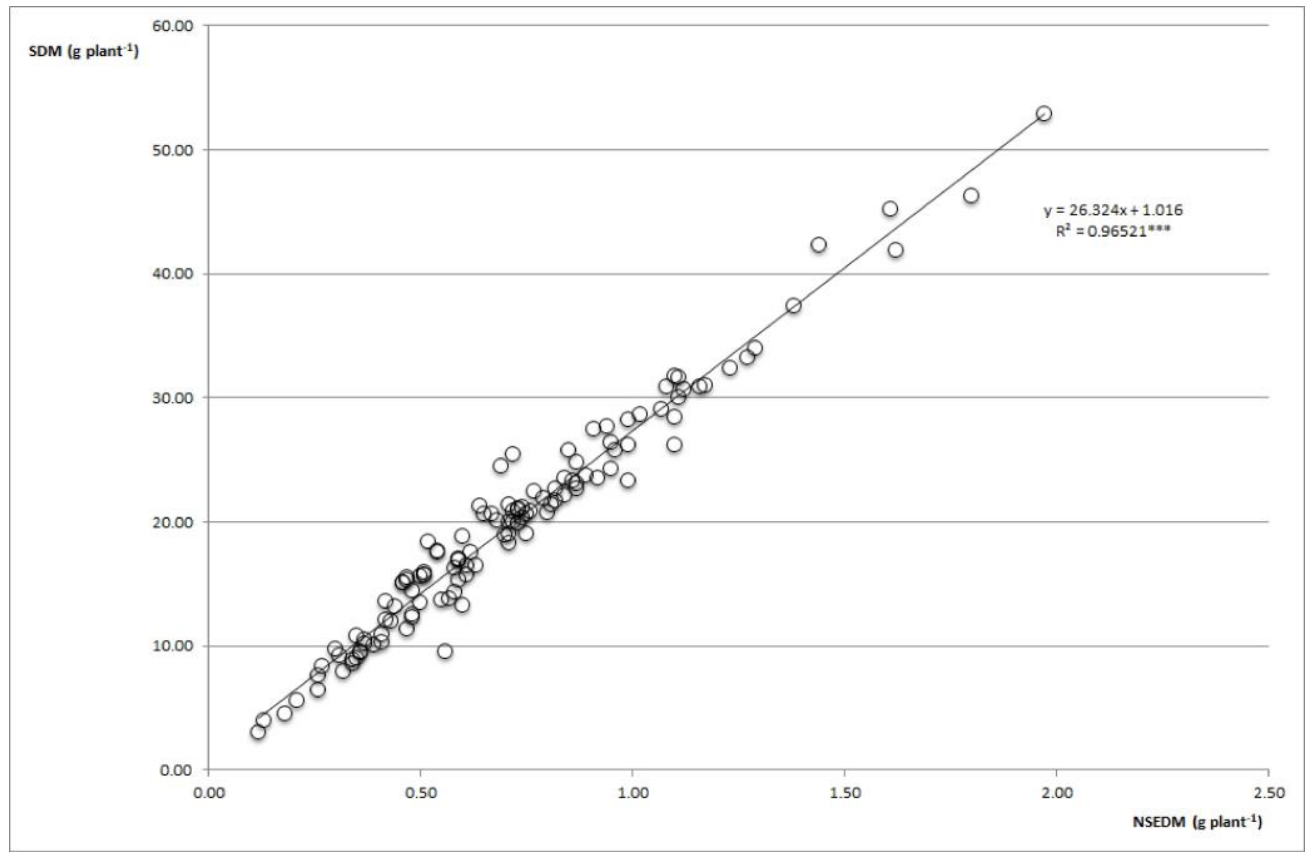

Figure 4. NSEDM vs. SDM ratio under water stress in the field. ${ }^{* * *} p<0.0001$.

\section{Conclusions}

None of the rhizobia strains provided the highest productivity in all genotypes. The main significant effect of the strains in the genotypes in the field implies important genotype-strain interspecificity.

The greenhouse experiment gives information on the symbiotic system under controlled conditions on some variables, which have been validated under field growing conditions. In the greenhouse, SNF was assessed by SDW. Neither the NN nor the NDW were correlated with the SDW due to the lack of homogeneity in the size of the nodules. The only exception was PHA-0683, which when the BNO phenotype presented its NDW if it was related to SDW. It is interesting to understand the mechanisms that produce BNO nodules and if the plant blocks non-functional nodules. The BNO phenotype may be more beneficial for plant growth and seed yield and it can be considered a trait for symbiosis efficiency.

These results were validated in the field. Thus, the best strains under irrigated conditions were LTMF, CIAT899 and EXIC and under water stress conditions they were APAFI, LTMF and EF. The best genotypes in irrigated conditions were PHA-0471, PMB0285 and PMB-0286 and in drought conditions they were PHA-0471, PMB-0222 and PMB0286. The growth of the inoculated strains is highly influenced by the $\mathrm{pH}$ and $\mathrm{P}$ of the soil [72-74]. Thus, some inoculum may have adaptation problems depending on the soil conditions. In low fertility soils, SNF is the main source of $\mathrm{N}$ in the plant. In the field, there was a relationship observed between NSEDM and SDM, so that N is a limiting factor for seed production. In general, the bean genotypes with the highest amount of nitrogen are the genotypes with the best seed production. The $\mathrm{N}$ content of the seed also indicates the amount of protein, important at a nutritional level. Under water stress, the inoculated genotypes with the strains LTMF, APAFI and EF presented high values of these variables. The genotypes with higher production and higher nitrogen fixation in drought conditions were PHA-0471, PHA-0683, PMB-0220, PMB-0222, PMB-0285 and PMB-0286. The best strain-genotype combination under drought conditions was APAFIPMB-0286. Under water stress, the most affected strain and genotypes were CIAT 899 and PMB-0244, respectively.

Only PHA-0483 with control N presented a high value because there was no optimal strain for this genotype in this trial. PHA-0155, inoculated with rhizobia, have a nitrogen 
content higher than the control with $\mathrm{N}$ supplement, both under irrigated and water stress conditions. Local strains have achieved maximum yield with some varieties, thus highlighting their possible use as inoculants. Thus, the results of this work could be the basis for obtaining an effective rhizobia biofertilizer for beans, with benefits for bean production and the environment. The biofertilization implies a lower cost in nitrogen fertilizers and reduces water pollution and the emission of greenhouse nitrogen gases.

Supplementary Materials: The following are available online at https:/ / www.mdpi.com/2073-439 5/11/1/70/s1, Table S1: Mean values and mean comparison of the variables studied in greenhouse without water stress, Table S2: Mean values and mean comparison of the variables studied in greenhouse under water stress, Table S3: Mean values and mean comparison of the variables studied in field without water stress, Table S4: Mean values and mean comparison of the variables studied in field under water stress.

Author Contributions: A.P.R.: manuscript redaction and interpretation of results, M.R.: management of the experimental work and interpretation of results, A.M.D.R.: manuscript revision and interpretation of results. All authors have read and agreed to the published version of the manuscript.

Funding: Projects PGIDIT06RAG40301PR and INCITE07PXI403088ES, Xunta de Galicia, Spain.

Data Availability Statement: Data is contained within the article or supplementary material. The data presented in this study are available in: Implications of the Symbiotic Nitrogen Fixation in Common Bean under Seasonal Water Stress.

Acknowledgments: Xunta de Galicia (Spain) for the use of the experimental fields, greenhouses and laboratories at the Experimental Agricultural Station Baixo Miño-INGACAL, Salceda de Caselas, Spain.

Conflicts of Interest: The authors declare no conflict of interest.

\section{References}

1. Duke, J.A. Handbook of Legumes of World Economic Importance; Plenum Press: New York, NY, USA, 1981.

2. Wondatir, Z.; Mekasha, Y. Feed resources availability and livestock production in the central rift valley of Ethiopia. Int. J. Livest. Prod. 2014, 5, 30-35. [CrossRef]

3. Beebe, S.E.; Rao, I.M.; Blair, M.W.; Acosta-Gallegos, J.A. Phenotyping common beans for adaptation to drought. Front. Physiol. 2013, 4, 1-20. [CrossRef] [PubMed]

4. Sánchez-Reinoso, A.D.; Ligarreto-Moreno, G.A.; Restrepo-Díaz, H. Evaluation of drought índices to identify tolerant geno-types in common bean bush (Phaseolus vulgaris, L.). J. Integr. Agric. 2020, 19, 99-107. [CrossRef]

5. Asfaw, A.; Blair, M.W. Quantification of drought tolerance in Ethiopian common bean varieties. Agric. Sci. 2014, 5, 124-139. [CrossRef]

6. White, J.W.; Singh, S.P. Breeding for adaptation to drought. In Common Beans: Research for Crop Improvement; Van Shoonhoven, A., Voysest, O., Eds.; CABI: Wallingford, UK; CIAT: Cali, Colombia, 1991; pp. 501-560.

7. Cuellar-Ortiz, S.M.; Arrieta-Montiel, M.D.L.P.; Acosta-Gallegos, J.; Covarrubias, A.A. Relationship between carbohydrate partitioning and drought resistance in common bean. Plant Cell Environ. 2008, 31, 1399-1409. [CrossRef] [PubMed]

8. Asfaw, A.; Demissie, D.A.; Shah, T.; Blair, M. Trait associations in diversity panels of the two common bean (Phaseolus vulgaris L.) gene pools grown under well-watered and water-stress conditions. Front. Plant Sci. 2017, 8, 733. [CrossRef] [PubMed]

9. Miklas, P.N.; Kelly, J.D.; Beebe, S.E.; Blair, M.W. Common bean breeding for resistance against biotic and abiotic stresses: From classical to MAS breeding. Euphytica 2006, 147, 105-131. [CrossRef]

10. Muñoz-Perea, C.G.; Terán, H.; Allen, R.G.; Wright, J.L.; Westermann, D.T.; Singh, S.P. Selection for Drought Resistance in Dry Bean Landraces and Cultivars. Crop. Sci. 2006, 46, 2111-2120. [CrossRef]

11. Nielsen, D.C.; Nelson, N.O. Black Bean Sensitivity to Water Stress at Various Growth Stages. Crop Sci. 1998, 38, 422-427. [CrossRef]

12. Yonts, C.D. Deficit Irrigation of Dry Edible Beans during Early, Mid and Late Season. In Proceedings of the 5th National Decennial Irrigation Conference Proceedings, Phoenix, AZ, USA, 5-8 December 2010; American Society of Agricultural and Biological Engineers (ASABE): St. Joseph, MI, USA, 2010; p. 1.

13. Broughton, W.J.; Zhang, F.; Perret, X.; Staehelin, C. Signals exchanged between legumes and Rhizobium: Agricultural uses and perspectives. Plant Soil 2003, 252, 129-137. [CrossRef]

14. Martínez-Romero, E. Diversity of Rhizobium-Phaseolus vulgaris symbiosis: Overview and perspectives. Plant Soil 2003, 252, 11-23. [CrossRef]

15. Kuykendall, L.D. Family I Rhizobiaceae. In Bergey's Manual of Systematic Bacteriology, 2rd ed.; Garrity, G., Krieg, N.R., Holt, J.G., Eds.; Springer: New York, NY, USA, 2005; pp. 324-340, ISBN 9780387241456. 
16. Herrera-Cervera, J.A.; Caballero-Mellado, J.; Laguerre, G.; Tichy, H.-V.; Requena, N.; Amarger, N.; Martínez-Romero, E.; Olivares, J.; Sanjuán, J. At least five rhizobial species nodulate Phaseolus vulgaris in a Spanish soil. FEMS Microbiol. Ecol. 1999, 30, 87-97. [CrossRef]

17. Drevon, J.J.; Alkama, N.; Bargaz, A.; Rodiño, A.P.; Sungthongwises, K.; Zaman-Allah, M. The Legume-Rhizobia Symbiosis. In Grain Legumes; De Ron, A.M., Ed.; Springer Science + Business Media: New York, NY, USA, 2015.

18. Kaymakanova, M.; Mincheva, T. Salinity and its effects on the physiological response of bean (Phaseolus vulgaris L.). J. Cent. Eur. Agric. 2008, 9, 749-755.

19. Wilmowicz, E.; Kucko, A.; Golinska, P.; Burchardt, S.; Przywieczerski, T.; Świdziński, M.; Brzozowska, P.; Kapuścińska, D. Abscisic acid and ethylene in the control of nodule-specific response on drought in yellow lupine. Environ. Exp. Bot. 2020, 169, 103900. [CrossRef]

20. Bouhmouch, I.; Souad-Mouhsine, B.; Brhada, F.; Aurag, J. Influence of host cultivars and Rhizobium species on the growth and symbiotic performance of Phaseolus vulgaris under water stress. J. Plant Physiol. 2005, 162, 1103-1113. [CrossRef]

21. Chemining, G.N.; Vessey, J.K. The abundance and efficacy of Rhizobium leguminosarum bv. viciae in cultivated soils of the eastern Canadian prairie. Soil Biol. Biochem. 2006, 38, 294-302.

22. SAS Institute Inc. SAS/STAT 15.1; SAS Institute Inc.: Cary, NC, USA, 2018.

23. Steel, R.G.D.; Torrie, J.H.; Dickey, D.A. Principle and Procedures of Statistics: A Biometrical Approach, 3rd ed.; Mc Graw Hill: New York, NY, USA, 1997; p. 666, ISBN 0070610282.

24. Hungria, M.; Franchini, J.C.; Campo, R.J.; Crispino, C.C.; Moraes, J.Z.; Sibaldelli, R.N.; Mendes, I.C.; Arihara, J. Nitrogen nutrition of soybean in Brazil: Contributions of biological N2 fixation and N fertilizer to grain yield. Can. J. Plant Sci. 2006, 86, 927-939. [CrossRef]

25. Rodiño, A.P.; De La Fuente, M.; De Ron, A.M.; Lema, M.J.; Drevon, J.-J.; Santalla, M. Variation for nodulation and plant yield of common bean genotypes and environmental effects on the genotype expression. Plant Soil 2011, 346, 349-361. [CrossRef]

26. Van Kessel, C.; Hartley, C. Agricultural management of grain legumes: Has it led to an increase in nitrogen fixation? Field Crops Res. 2000, 65, 165-181. [CrossRef]

27. Rengel, Z. Breeding for better symbiosis. Plant Soil 2002, 245, 147-162. [CrossRef]

28. Dorcinvil, R.; Sotomayor-Ramírez, D.; Beaver, J. Agronomic performance of common bean (Phaseolus vulgaris L.) lines in an Oxisol. Field Crops Res. 2010, 118, 264-272. [CrossRef]

29. Mostasso, L.; Mostasso, F.L.; Dias, B.G.; Vargas, M.A.; Hungria, M. Selection of bean (Phaseolus vulgaris L.) rhizobial strains for the Brazilian Cerrados. Field Crops Res. 2002, 73, 121-132. [CrossRef]

30. Oka-Kira, E.; Kawaguchi, M. Long-distance signaling to control root nodule number. Curr. Opin. Plant Biol. 2006, 9, 496-502. [CrossRef] [PubMed]

31. Bourion, V.; Laguerre, G.; Depret, G.; Voisin, A.S.; Salon, C.; Duc, G. Genetic variability in nodulation and root growth affects nitrogen fixation and accumulation in pea. Ann. Bot. 2007, 100, 589-598. [CrossRef] [PubMed]

32. Schultze, M.; Kondorosi, A. Regulation of symbiotic root nodule development. Annu. Rev. Genet. 1998, 32, 33-57. [CrossRef] [PubMed]

33. Sinclair, T.R.; Purcell, L.C.; King, C.A.; Sneller, C.H.; Chen, P.; Vadez, V. Drought tolerance and yield increase of soybean resulting from improved symbiotic N2 fixation. Field Crops Res. 2007, 101, 68-71. [CrossRef]

34. Mahieu, S.; Germon, F.; Aveline, A.; Hauggaard-Nielsen, H.; Ambus, P.; Jense, E.S. The influence of water stress on biomass and $\mathrm{N}$ accumulation, $\mathrm{N}$ partitioning between above and below ground parts and on $\mathrm{N}$ rhizodeposition during reproductive growth of pea (Pisum sativum L.). Soil Biol. Biochem. 2008, 41, 380-387. [CrossRef]

35. Voisin, A.S.; Munier-Jolain, G.; Salon, C. The nodulation process is tightly adjusted to plant growth an analysis using environmentally and genetically induced variation of nodule. Plant Soil 2010, 337, 399-412. [CrossRef]

36. Voisin, A.-S.; Bourion, V.; Duc, G.; Salon, C. Using an Ecophysiological Analysis to Dissect Genetic Variability and to Propose an Ideotype for Nitrogen Nutrition in Pea. Ann. Bot. 2007, 100, 1525-1536. [CrossRef]

37. Graham, P.H. Ecology of the Root-Nodule Bacteria of Legumes. In Nitrogen-Fixing Leguminous Symbioses; Springer: Berlin/Heidelberg, Germany, 2008; pp. 23-58. [CrossRef]

38. Muchero, W.; Ehlers, J.; Close, T.J.; Roberts, P.A. Mapping QTL for drought stress-induced premature senescence and ma-turity in cowpea. Theor. Appl. Genet. 2009, 118, 849-863. [CrossRef]

39. Muchero, W.; Ehlers, J.D.; Roberts, P.A. Restriction site polymorphism-based candidate gene mapping for seedling drought tolerance in cowpea [Vigna unguiculata (L.) Walp.]. Theor. Appl. Genet. 2010, 120, 509-518. [CrossRef] [PubMed]

40. Mergaert, P.; Uchiumi, T.; Alunni, B.; Evanno, G.; Cheron, A.; Catrice, O.; Mausset, A.-E.; Barloy-Hubler, F.; Galibert, F.; Kondorosi, A.; et al. Eukaryotic control on bacterial cell cycle and differentiation in the Rhizobium-legume symbiosis. Proc. Natl. Acad. Sci. USA 2006, 103, 5230-5235. [CrossRef] [PubMed]

41. Park, S.O.; Coyne, D.P.; Jung, G.; Skroch, P.W.; Arnaud-Santana, E.; Steadman, J.R.; Ariyarathne, H.; Nienhuis, J. Mapping of QTL for Seed Size and Shape Traits in Common Bean. J. Am. Soc. Hortic. Sci. 2000, 125, 466-475. [CrossRef]

42. González, A.; Rodiño, A.; Santalla, M.; De Ron, A.M. Genetics of intra-gene pool and inter-gene pool hybridization for seed traits in common bean (Phaseolus vulgaris L.) germplasm from Europe. Field Crops Res. 2009, 112, 66-76. [CrossRef]

43. Michiels, J.; Dombrecht, B.; Vermeiren, N.; Xi, C.; Luyten, E.; Vanderleyden, J. Phaseolus vulgaris is a non-selective host for nodulation. FEMS Microbiol. Ecol. 1998, 26, 193-205. [CrossRef] 
44. Graham, P. Some problems of nodulation and symbiotic nitrogen fixation in Phaseolus vulgaris L.: A review. Field Crops Res. 1981, 4, 93-112. [CrossRef]

45. Romdhane, S.B.; Aouani, M.E.; Trabelsi, M.; de Lajudie, P.; Mhamdi, R. Selection of high nitrogen-fixing Rhizobia modulating chickpea (Cicer arietinum) for Semi-Arid Tunisia. J. Agron. Crop Sci. 2008, 194, 413-420.

46. Hungria, M.; Campo, R.J.; Mendes, I.C. Benefits of inoculation of the common bean (Phaseolus vulgaris) crop with efficient and competitive Rhizobium tropici strains. Biol. Fertil. Soils 2003, 39, 88-93. [CrossRef]

47. Rennie, R.J.; Kemp, G.A. $\mathrm{N}_{2}$-Fixation in Field Beans Quantified by ${ }_{15}$ N Isotope Dilution. II. Effect of Cultivars of Beans 1 . Agron. J. 1983, 75, 645-649. [CrossRef]

48. Vessey, J.K. Cultivar differences in assimilate partitioning and capacity to maintain N2 fixation rate in pea during pod-filling. Plant Soil 1992, 139, 185-194. [CrossRef]

49. Araya, T.; Noguchi, K.; Terashima, I. Effect of nitrogen nutrition on the carbohydrate repression of photosynthesis in leaves of Phaseolus vulgaris L. J. Plant Res. 2009, 123, 371-379. [CrossRef] [PubMed]

50. Hardarson, G.; Atkins, G. Optimising biological N2 fixation by legumes in farming systems. Plant Soil 2003, 252, 41-54. [CrossRef]

51. Mutschler, M.A.; Bliss, F.A. Inheritance of bean seed globulin content and its relationship to protein content on quality. Crop Sci. 1981, 21, 289-294. [CrossRef]

52. Escribano, M.; Santalla, M.; De Ron, A.M. Genetic diversity in pod and seed quality traits of common bean populations from northwestern Spain. Euphytica 1997, 93, 71-81. [CrossRef]

53. Vasilas, B.L.; Nelson, R.L.; Fuhrmann, J.J.; Evans, T.A. Relationship of Nitrogen Utilization Patterns with Soybean Yield and Seed-Fill Period. Crop Sci. 1995, 35, 809-813. [CrossRef]

54. Kurdali, F.; Kalifa, K.; Al-Shamma, M. Cultivar differences in nitrogen assimilation, partitioning and mobilization in rain-fed grown lentil. Field Crops Res. 1997, 54, 235-243. [CrossRef]

55. Naya, L.; Ladrea, R.; Ramos, J.; González, E.M.; Arrese-Igor, C.; Minchin, F.R.; Becana, M. The response of carbon metabolism and antioxidant defenses of alfalfa nodules to drought stress and to the subsequent recovery of plants. Plant Physiol. 2007, 144, 1104-1114. [CrossRef]

56. Singh, S.P. Drought Resistance in the Race Durango Dry Bean Landraces and Cultivars. Agron. J. 2007, 99, 1219-1225. [CrossRef]

57. Sadras, V.O. Evolutionary aspects of the trade-off between seed size and number in crops. Field Crops Res. 2007, 100, 125-138. [CrossRef]

58. Harper, L.A.; Giddens, J.E.; Angdale, G.W.; Sharpe, R.R. Environmental effects on nitrogen dynamics in soybean under conservation and clean tillage systems. Agron. J. 1989, 81, 623-631. [CrossRef]

59. Boutraa, T.; Sanders, F.E. Effects of interactions of moisture regime and nutrient addition on nodulation and carbon partitioning in two cultivars of bean (Phaseolus vulgaris L.). J. Agron. Crop Sci. 2001, 186, 229-237. [CrossRef]

60. Silva, A.d.N.; Gerosa, M.L.; Ribeiro, W.Q.; Rodrigues, E.; Carvalhoda, P.; Andreade, C.; Cleo, C.; Vanderlei, M.A. Water stress alters physical and chemical quality in grains of common bean, triticale and wheat. Agric. Water Manag. 2020, $231,106023$. [CrossRef]

61. Hungria, M.; Vargas, M.A. Environmental factors affecting N2 fixation in grain legumes in the tropics, with an emphasis on Brazil. Field Crops Res. 2000, 65, 151-164. [CrossRef]

62. Mnasri, B.; Aouani, M.E.; Mhamdi, R. Nodulation and growth of common bean (Phaseolus vulgaris) under water deficiency. Soil Biol. Biochem. 2007, 39, 1744-1750. [CrossRef]

63. Güereña, D.T.; Lehmann, J.; Thies, J.E.; Vanek, S.; Karanja, N.; Neufeldt, H. Nodulation of beans with inoculant carriers from pyrolyzed and non-pyrolyzed sugarcane bagasse in response to different pre-planting water availability. Appl. Soil Ecol. 2019, 143, 126-133. [CrossRef]

64. Kipe-Nolt, J.A.; Vargas, H.; Giller, K.E. Nitrogen fixation in breeding lines of Phaseolus vulgaris L. Plant Soil 1993, 152, $103-106$. [CrossRef]

65. Sinclair, T.R.; Muchow, R.C.; Ludlow, M.M.; Leach, G.J.; Lawn, R.J.; Foale, M.A. Field and model analysis of the effect of water deficits on carbon and nitrogen accumulation by soybean, cowpea and black gram. Field Crops Res. 1987, 17, 121-140. [CrossRef]

66. Pfeiffer, N.E.; Malik, N.S.A.; Wagner, F.W.; Wang, C.Y.; Adams, D.O. Reversible Dark-Induced Senescence of Soybean Root Nodules. Plant Physiol. 1983, 71, 393-399. [CrossRef]

67. Kumarasinghe, K.S.; Danso, S.K.A.; Zapata, F. Field evaluation of fixation and N partitioning in climbing bean (Phaseolus vulgaris L.) using 15N. Biol. Fertil. Soils 1992, 13, 142-146.

68. Ramos, M.L.G.; Gordon, A.J.; Minchin, F.R.; Sprent, J.I.; Parsons, R. Effect of water stress on nodule physiology and bio-chemistry of a drought tolerant cultivar of common bean (Phaseolus vulgaris L.). Ann. Bot. 1999, 83, 57-63. [CrossRef]

69. Gálvez, L.; González, E.M.; Arrese-Igor, C. Evidence for carbon flux shortage and strong carbon/nitrogen interactions in pea nodules at early stages of water stress. J. Exp. Bot. 2005, 56, 2551-2561. [CrossRef] [PubMed]

70. Peña-Cabriales, J.J.; Castellanos, J.Z. Effects of water stress on N2 fixation and grain yield of Phaseolus vulgaris L. In Enhancement of Biological Nitrogen Fixation of Common Bean in Latin America; Springer: Dordrecht, The Netherlands, 1993; Volume 52, pp. 151-155. [CrossRef]

71. Araújo, A.P.; Teixeira, M.G. Nitrogen and phosphorus harvest indices of common bean cultivars: Implications for yield quantity and quality. Plant Soil 2003, 257, 425-433. [CrossRef] 
72. Vadez, V.; Drevon, J.J. Genotypic variability in phosphorus use efficiency for symbiotic N2 fixation in common bean (Phaseolus vulgaris). Agronomie 2001, 21, 691-699. [CrossRef]

73. Remans, R.; Croonenborghs, A.; Gutierrez, R.T.; Michiels, J.; Vanderleyden, J. Effects of plant growth-promoting rhizobacteria on nodulation of Phaseolus vulgaris L. are dependent on plant P nutrition. Eur. J. Plant Pathol. 2007, 119, 341-351. [CrossRef]

74. Wakelin, S.A.; Macdonald, L.; Rogers, S.; Gregg, A.; Bolger, T.; Baldock, J. Habitat selective factors influencing the structural composition and functional capacity of microbial communities in agricultural soils. Soil Biol. Biochem. 2008, 40, 803-813. [CrossRef] 